\title{
The American Association for Thoracic Surgery 2016 ethics forum: Working virtues in surgical practice
}

\author{
Larry R. Churchill, PhD
}

\begin{abstract}
Moral virtues are the complement to ethical principles. They constitute the elements of character that drive habits and daily routines. Certain virtues are especially important in surgery, shaping surgical practice even when no big decisions are at hand. Eight virtues are described and the work they do is explored: trustworthiness, equanimity, empathy, advocacy, compassion, courage, humility, and hope. (J Thorac Cardiovasc Surg 2017;153:1214-7)
\end{abstract}

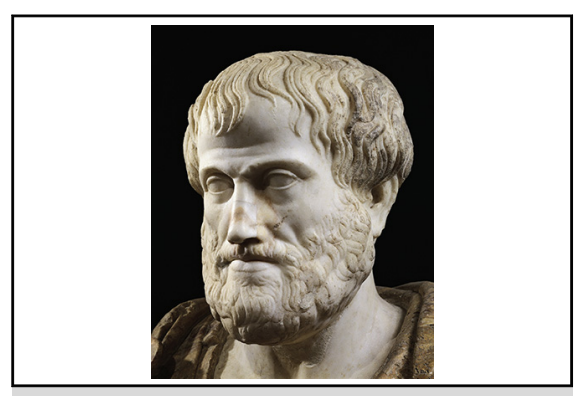

We are what we repeatedly do. Moral excellence, then, is not an act, but a habit. - Aristotle 384-322 BC.

Central Message

Moral virtues are character traits that shape the routines of surgical practice. This essay explores the special ethical work done by the most important of these virtues.

See Editorial Commentary page 1218
Surgical ethics is usually understood as the application of moral principles to problems that arise in patient care. The American Association for Thoracic Surgery (AATS) Code of Ethics notes principles such as duties to protect patient confidentiality, to maximize patient welfare, and to minimize potential harms. ${ }^{1}$ Although important, principled thinking is only a part of ethics. The other part is the practice of virtues, those dispositions and habits of character that shape a surgeon as a moral agent. Virtues focus less on what surgeons do and more on who they are; that is, the character-driven aspects of morality that lie behind choices and decisions. The AATS Code of Ethics notes the need for acting "in good faith," and "with compassion." 1 These are examples of surgeon virtues. Virtues are the constant background feature of ethics, those habits

From the Center for Biomedical Ethics and Society, Vanderbilt University Medical Center, Nashville, Tenn.

Read at the 96th Annual Meeting of The American Association for Thoracic Surgery, Baltimore, Maryland, May 14-18, 2016.

Received for publication July 29, 2016; revisions received Aug 24, 2016; accepted for publication Sept 1, 2016; available ahead of print Oct 5, 2016.

Address for reprints: Larry R. Churchill, PhD, Center for Biomedical Ethics and Society, Vanderbilt University Medical Center, 2525 West End Ave, Ste 400, Nashville, TN 37203 (E-mail: larry.churchill@ vanderbilt.edu).

0022-5223/\$36.00

Copyright (c) 2016 by The American Association for Thoracic Surgery

http://dx.doi.org/10.1016/j.jtcvs.2016.09.015 that are at work even when principles are not in play; that is, when no important decision needs to be made. Thus, although principles focus on important values in decision making, virtues motivate and predispose surgeons to good decisions by informing routine practices. Thus, a disposition to the virtue of honesty helps to frame a principled choice of truth-telling when the truth may be hard to tell and difficult to hear. Principles constitute the superstructure of ethics; virtues compose the infrastructure. Principles involve head work, requiring consistent and judicious application. Virtues constitute the heart work, those features of character that motivate and impel moral activity. These 2 aspects of ethics are integrally related. As Aristotle put it, it is the dispositions and habits of a good character that allow us to use the principles of ethics wisely. ${ }^{2}$

Two recent, excellent books on surgical ethics include lists of virtues. Sade's 2015 volume The Ethics of Surgery: Conflicts and Controversies ${ }^{3}$ singles out 6 virtues as central: respect for a patient's right to decide; integrity, defined as consistency of beliefs and actions; honesty; cognitive and technical competence; compassion; and trustworthiness. This last virtue Sade considers the summation of the other virtues. ${ }^{3}$ The Ethics of Surgical Practice, a 2008 volume by Jones, McCullough, and Richman ${ }^{4}$ 


\section{Abbreviation and Acronym \\ AATS $=$ The American Association for Thoracic Surgery}

emphasizes 4 virtues as particularly important: integrity, compassion, self-effacement, and self-sacrifice. Each virtue in both lists is important; I would not argue against the salience or usefulness of any of them. Indeed, a part of the challenge of naming virtues is that there are so many one can easily imagine as worthwhile. A complete list would be lengthy and likely unhelpful, because different situations and contexts of practice will call for the exercise of different traits of character. My task here is more modest than providing a complete or definitive list. I will highlight 8 virtues I consider fundamental to surgical practice. My purpose is not simply to name them, but to give some indication of the moral labor they perform; that is, their ethical function. Hence the stress in the title of this article on working virtues, focusing on the specific good that is achieved when each is embraced and practiced.

\section{EIGHT FUNDAMENTAL VIRTUES}

My candidates for the fundamental or basic virtues are as follows: trustworthiness, equanimity, empathy, advocacy, compassion, courage, humility, and hope, keeping in mind that each of these virtues carries a set of moral lessons. I will explicate and briefly argue for the importance of each in turn.

\section{Trustworthiness}

$\mathrm{Sade}^{3}$ is right to think this virtue is in some sense a summation of the others, especially if we consider that without it little or nothing can be accomplished with patients. Physicians, and especially surgeons, need to establish that they are worthy of a patient's fiduciary investment. No reasonable patient who has an alternative would proceed with a surgical procedure without some assurance that the surgeon will faithfully and consistently act for his/her benefit. I place trustworthiness first because it is temporally first in a clinical encounter. It gets established very quickly, usually in the first several minutes of the initial meeting between doctor and patient. ${ }^{5}$ As a result, trustworthiness lays the foundation for all the conversations about diagnosis and prognosis and the recommendations for treatments that follow. Interviews indicate that the initial sense by patients that a physician can be trusted is grounded in surprisingly small things. Smiling; greeting the patient and family in a warm, welcoming way; and showing interest in the unique person behind the presenting symptoms are all essential to establishing trustworthiness. Establishing this fiduciary bond early in a relationship can pay dividends in terms of history taking and subsequent quality of care. One patient reported, "I knew from the first time I met her [the surgeon] that she cared about me, so I could tell her things I wouldn't tell other doctors." 6

\section{Equanimity}

The ideal of calmness under pressure has long been a staple of medical ethics. It was given prominent modern expression in Osler's valedictory address at the University of Pennsylvania in 1889, which was titled "Aequanimitas." 7 A Latin term, aequanimitas means to possess an even soul, a steadiness of mind in a world of turmoil and uncertainty. In patient interviews more than half of our informants cited calmness as an important physician trait. One patient put it this way: "If physicians can be still and focused it creates an envelope in which it is safe to be there, and that allows me to be completely honest about what is going on." ${ }^{8}$ Needless to say, cardiothoracic surgeons have a special use for this virtue. In addition to its effect on patients, the effects of equanimity on one's surgical team and on one's self are equally or even more important.

\section{Empathy}

This virtue is not just high on my list for surgeons, it is sine qua non for ethics generally. Empathy is the ability to discern what another person is thinking and feeling, or more broadly, to discern something of what his/her life is like. It is, as the saying goes, the ability to walk a mile in another person's shoes. Empathy has both cognitive and emotional facets. It is sometimes confused with its near cousin, sympathy, which is more a matter of feeling what others are feeling, an echoing of sentiment, such as feeling sad in the presence of others who are sad. Empathy is not sameness of feeling, but awareness of what it is like for others. It involves cognitive and imaginative skills, a curiosity about, and an openness to, the lives of others. Exercises of empathy require the effort to reach out for and acknowledge another person's situation, such as a patient's pain, fear, frustration, or uncertainty. The capacity for empathy is a part of our evolutionary inheritance, but its realization as a skill requires routine practice, just like palpating a liver or suturing a wound. With this understanding it is easy to see how empathy works to enhance trustworthiness and-as I will argue later-to promote compassion.

\section{Advocacy}

The medical systems of the 21st century are complex, and largely user-unfriendly. Medical care itself is often subdivided among specialists who do not always communicate with each other, much less translate diagnostic and prognostic information to patients. It is easy for patients to get 
lost in systems not designed for their accessibility but for provider convenience, efficiency, and profitability. All patients from time to time need an advocate, and seriously ill patients typically need a medical advocate, as well as a family member or friend who will persist in asking questions and clarifying answers. Surgeons are essential to advocacy, but that does not mean they need to personally undertake all the tasks of advocacy themselves. More than other virtues, advocacy is spread across teams, and the specific tasks can often be provided by primary care physicians, nurses, social workers, or chaplains. A surgeon's role is often one of establishing the tone and standard for advocacy within the larger team.

\section{Compassion}

Compassion is a central virtue in every major world religion, and is no less central to surgical practice. The work it does is to express care and affection, which are central components of healing. The English term compassion has its etymological roots in Greek and Latin phrases meaning "to suffer together with." I said earlier that empathy is the gateway to compassion. Empathy helps a surgeon recognize and accurately locate suffering, whereas compassion is the response that helps to heal the suffering. All surgical interventions should be seen as essentially gestures of compassion insofar as they are aimed to alleviate suffering. But compassion also requires a verbal expression to make its intention clear. Giving voice to compassion can make a major difference, because it builds solidarity with patients in their efforts to cope with their illnesses and disabilities. For example, words of encouragement such as, "You're a brave person to put up with this pain," or, "I admire the way you are taking responsibility for your care," are essentially expressions of compassion. They can go a long way to restoring patients to the best selves they can be, even when surgical interventions are not completely successful.

\section{Courage}

Poet Maya Angelou recognized that courage holds a special place among the virtues. She put it this way: "Courage is the most important of the virtues because without courage you can't practice any other virtue consistently." Most of us think of courage as entailing large, dramatic acts, such as Captain Sullenberger safely landing a floundering passenger jet on the Hudson River. ${ }^{10}$ But what Sullenberger said about his actions that day underscore the recognition that such acts are grounded in everyday habits. He said he had been preparing all his professional life for just such an eventuality. Courageous acts spring from a groundwork of careful preparation in routine practices. Courageous acts are the acts of courageous persons who have trained themselves to overcome their fears. Anything-large or small-that requires facing and working through one's fears is an act of courage. Surgeons, knowing that every operation has hazards and can result in patient harm, have more than a typical need for courage.

\section{Humility}

Humility is a fundamental part of self-knowledge. As an indicator of the limits of professional competence it highlights the real possibility of error and thereby opens a surgeon to recognition of mistakes. The classic study of errors and mistakes in surgery was published by Bosk in his 1979 book Forgive and Remember. ${ }^{11}$ Bosk $^{11}$ classifies errors as either technical or moral. A moral error is the more egregious because it usually involves the failure to admit to technical errors or recognize boundaries of competence. Humility is a virtue precisely because it functions in the service of avoiding moral errors by more accurately gauging the limits of skill and knowledge. At its heart humility does not connote self-abasement or servile humiliation, but simply accurate self-assessment. The opposite of humility is hubris and arrogance, rooted in an overestimate of one's skills or knowledge. Humility also works in surgery in another practical way: It helps to modify overly optimistic expectations about outcomes for both surgeons and patients. Nobel Laureates Kahneman and Tversky have shown that humans have excessive confidence in what we think we know and often underestimate the range of our ignorance and the large role that chance plays in events. ${ }^{12}$ If this is true, then humility is in the serve of a more mature and thoughtful realism. Chochinov, a palliative care physician, said it admirably: "Nothing promotes humility more effectively than the growing realization that little separates us from our patients." 13

\section{Hope}

Hopefulness is a fundamental demeanor that patients can read in a surgeon's tone and inflection, as well as his/her bodily posture. Perhaps more than other virtues, it is a visible character trait. Hope is not optimism, which has acquired the status of something like an official state ideology in the United States. ${ }^{14}$ Optimism is the conviction, often naïve, that anything is possible. This has been captured succinctly in a set of hospital billboard advertisements in Nashville, Tennessee, that boldly declare, glossing a Biblical passage, that "Nothing shall be impossible." Such flat-footed and unqualified promotions of optimism are unprofessional, and result in crushing disappointments and bitter irony when treatments fail, as they sometimes do. Optimism, in this respect, is related to lack of humility. Hope, by contrast, is an attitude of openness to something 
good or redeeming that can occur even in the face of discouraging facts or bad outcomes. ${ }^{15}$ Whereas the opposite of optimism is fear of failure, the opposite of hope is despair. Hope also needs to be distinguished from expectations, which do not always tilt in favor of good results. Some surgeons I have interviewed say they make a practice of asking patients 2 questions as a part of informed consent. The first is, "What do you think you can expect from this operation?" as a way of setting expectations realistically. The second is, "What do you hope for as a result of this surgery?" which often involves a larger life register than physiologic repair of an organ or vessel. For example, a patient may say, "I hope I can get back to work," or, "I hope for a few more good years." Validating this kind of existential hope in patients becomes easier if a surgeon can share it, even if it is not a likely expectation.

\section{CONCLUSIONS}

I propose an addition to the official AATS Code of Ethics in the form of an oath: Let me cultivate in myself and in my colleagues those elements of character that are most conducive to patient care and professional well-being: trustworthiness, equanimity, empathy, advocacy, compassion, courage, humility, and hope.

\section{Conflict of Interest Statement}

Author has nothing to disclose with regard to commercial support.

\section{References}

1. The American Association for Thoracic Surgery. Code of ethics. Available at: http://aats.org/Association/Policies/Code_of_Ethics.cgi. Accessed July 27, 2016

2. Aristotle. Nicomachean ethics. Irwin T, tans. Indianapolis: Hackett Publishing Company; 1985:44, 65.

3. Sade RM, ed. The ethics of surgery: conflicts and controversies. New York: Oxford University Press; 2015:2-3.

4. Jones JW, McCullough LB, Richman BW. The ethics of surgical practice: cases, dilemmas and resolutions. New York: Oxford University Press; 2008:6.

5. Schenck D, Churchill LR. Healers: extraordinary clinicians at work. New York: Oxford University Press; 2012:6-8.

6. Churchill LR, Fanning JB, Schenck D. What patients teach: the everyday ethics of health care. New York: Oxford University Press; 2013:41-3.

7. Osler W. Aequanimitas. Available at: http://www.medicalarchives.jhmi.edu/ osler/aequessay.htm. Accessed July 27, 2016.

8. Churchill LR, Fanning JB, Schenck D. What patients teach: the everyday ethics of health care. New York: Oxford University Press; 2013:33-4.

9. Kightlinger C. From Star archives: Maya Angelou on courage, poetry. Available at: http://www.indystar.com/story/life/2014/05/28/maya-angelo-courage-speechbutler/9664041/. Accessed July 27, 2016.

10. 'Sully' Sullenberger remembers the miracle on the Hudson. Available at: http:// www.newsweek.com/miracle-hudson-343489. Accessed July 27, 2016.

11. Bock CL. Forgive and remember: managing medical failure. Chicago: University of Chicago Press; 1979.

12. Kahneman D. Thinking fast and slow. New York: Farrar, Straus and Giroux 2013:13-4.

13. Chochinov HM. Humility and the practice of medicine: tasting humble pie. Can Med Assoc J. 2010;182:1217-8.

14. Eagleton T. Hope without optimism. Charlottesville: University of Virginia Press 2015:10.

15. Andre J. Worldly virtue: moral ideals and contemporary life. Lanham: Lexington Books; 2015:31-44.

Key Words: ethics, virtues, professionalism, patient care 